\title{
Association between Food Behaviour of Pregnant Women and Status of Serum Vitamin B12 and Neonatal Outcome - A Cross-Sectional Study
}

\author{
Rowshan Afrooz ' , Lipika Ghosh, ${ }^{2}$ Abul Kalam Md. Faruq, ${ }^{3}$ Mitheel-Ibna Islam ${ }^{4}$
}

\begin{abstract}
:
Background \& objective: To find the association between serum vitamin B12 and food behavior of the pregnant women and its influence on perinatal outcome.

Methods: This cross-sectional study was conducted in the Department of Obstetrics \& Gynaecology, Bangabandhu Sheikh Mujib Medical University (BSMMU), Dhaka between June 2012 to July 2013. A total of 102 uncomplicated pregnant women attending at the Obstetrics \& Gynaecology Department of BSMMU, Dhaka were the study population. Plasma vitamin B12 was measured by Abbott Axsym System using a Enzyme Immuno Assay Technique with the blood collected in a plain test tube. A serum vitamin B12 level of $<200 \mathrm{pg} / \mathrm{mL}$ was considered as low serum vitamin B12 level. The outcome variables were birth weight,
\end{abstract} small-for-date, neural tube defects and other congenital malformations.

Result: The selected pregnant women were housewife (74.5\%) from low socioeconomic strata. They were generally urban resident (90.2\%) with mean age being 26.4 years. In terms of education $17.6 \%$ were primary level, $30.4 \%$ SSC level, $31.4 \% \mathrm{HSC}$ level and $20.6 \%$ graduate and higher level educated. Majority $(90.2 \%)$ was urban resident with average monthly family income being Taka 29460 . One-third $(33.3 \%)$ was overweight and $6.9 \%$ obese. Two-thirds $(66.7 \%)$ were at 37-39 weeks of gestation and nullipara. More than $60 \%$ received ANC (antenatal care) aregularly. Over one-third $(35.3 \%)$ had low serum vitamin B12 $(<200$ $\mathrm{pg} / \mathrm{mL}$ ). The food behaviour of the women was found to be associated with vitamin B12 deficiency. The pregnant women with low serum vitamin $B_{12}(<200 \mathrm{pg} / \mathrm{ml})$ had significantly lower weekly consumption of fishes and eggs which are the rich source of vitamin B12. The weekly fish, eggs and amount of milk consumed by the pregnant women with low serum vitamin $B 12$ were much lower than those consumed by the pregnant women with normal serum vitamin $B_{12}$. The pregnant women with low serum vitamin $B 12$ were more likely to carry a higher risk of adverse perinatal outcome. The incidences of low-birth weight and small-for-dates were staggeringly higher in women with low serum vitamin $\mathrm{B} 12$ (33.3\% and $27.8 \%$ respectively) compared to those in women with normal serum vitamin B12.

Conclusion: The study concluded that pregnant women with low serum vitamin B12 are accustomed to taking low fish and eggs in their daily diet compared to those who have normal serum vitamin B12. The incidence of low birth weight and small-for-date babies are more prevalent in the pregnant women with subclinical deficiency of vitamin B12.

Key words: Food behaviour, pregnant women, serum vitamin B12 and neonatal outcome etc.

\section{Authors' information:}

' Dr. Rowshan Afrooz, MBBS, MS (Obstetrics \& Gynaecology), Assistant Professor, Obstetrics \& Gynaecology, Nightingle Medical College, Dhaka

${ }^{2}$ Dr. Lipika Ghosh, MBBS, MS (Obstetrics \& Gynaecology), Assistant Professor, Colonel Malek Medical College, Manikganj

${ }^{3}$ Dr. Abul Kalam Md. Faruq, BDS, MS (Oral \& Maxillofacial Surgery), Assistant Professor, Oral \& Maxillofacial Surgery, Dhaka Dental College, Dhaka.

${ }^{4}$ Dr. Mitheel-Ibna Islam, MBBS, FCPS (Obstetrics \& Gynaecology), DGO, Medical Officer, 250 Bed Shahid Shaikh Abu Naser Specialist Hospital, Khulna.

Correspondence: Dr. Rowshan Afrooz, Cell Phone: +88 01823883265, E-mail:dr.akmfaruq@yahoo.com 


\section{INTRODUCTION:}

Vitamin $B_{12}$ deficiency is emerging as a public health concern in many developing countries. A progressive reduction in plasma vitamin $B_{12}$ levels has been documented to occur during pregnancy despite maintenance of normal dietary intake of this vitamin. ${ }^{1,2} \mathrm{~A}$ review of studies in Latin America revealed that it occurs in $40 \%$ of women and their children due to low intake of animal sources of food. ${ }^{3}$ All the vitamin $B_{12}$ in nature is produced by microorganisms and it is found only in foods of animal origin and vegetables contaminated with vitamin $\mathrm{B}_{12}$-synthesizing bacteria. ${ }^{4}$

Vitamin $B_{12}$ is an essential nutrient in the diet of humans due to its important function as a coenzyme in the remethylation of homocysteine to methionine and in the conversion of methylmalonyl-CoA to succinal-CoA. It is involved in fatty acid degradation and protein and DNA synthesis. ${ }^{5}$ Deficiency of this nutrient is known to be associated with signs of demyelination, usually in the spinal cord. Lack of vitamin $B_{12}$ in the maternal diet during pregnancy has been shown to cause severe retardation of myelination in the nervous system of the fetus. ${ }^{6}$ Inadequate vitamin $B_{12}$ status during pregnancy has consequences for both the mother and the fetus. Vitamin $B_{12}$ deficiency is associated with increased risk for early recurrent abortion ${ }^{7}$ and preeclampsia in pregnant women ${ }^{8}$ and neural tube defects in infants. ${ }^{9-11}$ A tripling in the risk for neural tube defects was reported by Ray and coworkers for infants born to women in the lowest quartile of vitamin $B_{12}$ status compared with the highest quartile. $^{12}$

In contrast to other water-soluble vitamins, significant amounts of vitamin $\mathrm{B}_{12}$ are stored in the body. As a result, it may take several years for the clinical symptoms of $B_{12}$ deficiency to develop. Nevertheless, marginal vitamin $B_{12}$ status in pregnancy is of concern since the vitamin $B_{12}$ status of the mothers is associated with their fetal outcome. ${ }^{13}$
There are degrees of vitamin $\mathrm{B}_{12}$ deficiency. Overt clinical $B_{12}$ deficiency, the more serious form, is marked by haematological or neurological abnormalities, or both, and requires prompt medical treatment. However, clinically evident deficiency accounts for less than $10 \%$ of low vitamin $B_{12}$ concentrations observed in most surveys. ${ }^{14}$ Subclinical vitamin $B_{12}$ deficiency, the more common situation, is a state in which there is metabolic evidence of deficiency in a non-symptomatic patient, such as an elevated serum level of methylmelonic acid or homocysteine. ${ }^{15}$ The main cause of subclinical vitamin $B_{12}$ deficiency is a chronic low intake of dietary vitamin $\mathrm{B}_{12}$ and may not require medical intervention since it does not usually progress to clinical deficiency. ${ }^{14}$

As foods of animal origin, such as meat, milk and poultry are the main sources of dietary vitamin $\mathrm{B}_{12,}{ }^{16}$ knowledge concerning the vitamin $\mathrm{B}_{12}$ status of pregnant women is of particular importance in parts of the world where dietary vitamin $B_{12}$ is often low in foods from animal sources providing only marginal amounts of vitamin $\mathrm{B}_{12 .}{ }^{17}$ As Bangladesh is one of those parts of the world, where majority of people's daily dietary intake is poor in animal sources of foods leading them to suffer from vitamin $B_{12}$ deficiency, it is of utmost importance to study the level of vitamin $B_{12}$ status in pregnant women and its association with their food behaviour.

\section{METHODS:}

The present cross-sectional study was carried out in Department of Obstetrics \& Gynaecology, BSMMU Hospital, Dhaka, over a period of 1 year between July 2012 to June 2013. Pregnant women attending at the above mentioned Hospital were the study population. A total of 102 uncomplicated pregnant women at their third trimester who had previously booked (registered) with the antenatal clinic were included in the study. However, pregnant women with clinical diagnosis of chronic illness, such as, diabetes mellitus, hypertension, 
heart diseases, thyroid disorders and women with multiple pregnancies, proteinuria or any other pregnancy-related complications were excluded.

Information regarding age, gravidity and parity was obtained for each subject. Weight was measured to within $0.5 \mathrm{~kg}$ and height was measured to within $0.25 \mathrm{~cm}$, using a portable stadiometer. Gestational age was estimated using the data of the last menstrual period, early ultrasound findings and measurement of fundal height. A single blood sample of $3 \mathrm{ml}$ was collected by venepuncture in a plain test-tube tube for measurement of serum vitamin $B_{12}$. Neonates were examined and weighted to the nearest $10 \mathrm{gm}$ on a standard beam scale balance immediately after birth. Plasma vitamin $\mathrm{B}_{12}$ was measured by Abbott Axsym System using a Enzyme Immuno Assay Technique with the blood collected in plain test tube. A serum vitamin $B_{12}$ level of $<200 \mathrm{pg} / \mathrm{mL}$ was considered as low serum vitamin $B_{12}$. Data were processed and anlysed using SPSS (Statistical Package for Social Sciences), version 17. The test statistics used to analyse the data were Chi-square $\left(\chi^{2}\right)$ or Fisher's Exact Test and Unpaired t-Test. The data presented on categorical scale were compared between groups using Chi-square $\left(\chi^{2}\right)$ or Fisher's Exact Test, while the data presented on continuous scale were compared between groups using Unpaired t-Test. Level of significance was set at 0.05 and $\mathrm{p}<0.05$ was considered significant.

\section{RESULTS:}

The pregnant women included in the study were generally housewife $(74.5 \%)$, urban resident $(90.2 \%)$ with mean age being 26.4 years. In terms of education $17.6 \%$ were primary level, $30.4 \%$ SSC level, $31.4 \%$ HSC level and $20.6 \%$ graduate and higher level educated. Average monthly family income was Taka 29460. Nearly $60 \%$ of the women were of normal BMI followed by $33.3 \%$ overweight and $6.9 \%$ obese(Table I). Two-thirds $(66.7 \%)$ of the pregnant women were at $37-39$ weeks of gestation, $25.5 \%$ were $40-41$ weeks and $7.8 \%$ were $34-36$ weeks of gestation. In terms of parity $65 \%$ were nullipara, $14.7 \%$ primipara and $19.6 \%$ multipara. More than $60 \%$ received ANC regularly and $39.2 \%$ received it irregularly (Table II).

Out of 102 pregnant women, 36(35.3\%) had low serum vitamin $B_{12}$ and the rest 66(64.7\%) had normal level of vitamin $B_{12}$. The mean serum vitamin $B_{12}$ was $208 \mathrm{pg} / \mathrm{ml}$ and the lowest and highest values were 60 and $294.4 \mathrm{pg} / \mathrm{ml}$ respectively (Table III). There was no significant difference between pregnant women with low and normal vitamin $B_{12}$ status in terms of their age ( $p$ $=0.252$ ). However, mean monthly income was significantly lower in the former group than that in the latter group $(p<0.001)$. Over $70 \%$ of women with low serum vitamin $B_{12}$ status were low level educated (primary and SSC level) as opposed to women with normal vitamin $B_{12}$ status (44\%) ( $p=$ 0.049 ). The parity and BMI were not found to be associated serum vitamin $B_{12}$ status of pregnant women ( $p=0.970$ and $p=0.124$ respectively) (Table IV).The median fish day in a week was observed to be lower in women with low vitamin $B_{12}$ status than that in women with normal vitamin $B_{12}(p<0.001$ and $p<0.001)$. The mean number of eggs and amount of milk consumed in a week were also less in pregnant women with low vitamin $\mathrm{B}_{12}$ status than that in women with normal vitamin $B_{12}$ level $(p<0.001 \& p=0.001$ respectively). However, median meat days in a week was almost similar between the groups ( $p=$ 0.301) (Table V).

The prevalence of low birth weight was significantly higher in women with low serum vitamin $B_{12}$ than that in women with normal vitamin $B_{12}$ level $(p<0.001)$. The proportion of small-for-date was also much higher in the former group ( $p=0.002)$. Neural tube defects and congenital malformation were no different between the groups $(p=0.133$ and $p=0.279$ respectively) (Table VI). 


\begin{tabular}{|c|c|c|}
\hline Sociodemographic features & Frequency & Percentage \\
\hline \multicolumn{3}{|l|}{ Age* (years) } \\
\hline$<20$ & 12 & 11.8 \\
\hline $20-30$ & 60 & 58.8 \\
\hline$\geq 30$ & 30 & 29.4 \\
\hline \multicolumn{3}{|l|}{ Maternal occupation } \\
\hline Service & 26 & 25.5 \\
\hline Housewife & 76 & 74.5 \\
\hline \multicolumn{3}{|l|}{ Education } \\
\hline Primary & 18 & 17.6 \\
\hline SSC & 31 & 30.4 \\
\hline $\mathrm{HSC}$ & 32 & 31.4 \\
\hline Graduate plus & 21 & 20.6 \\
\hline \multicolumn{3}{|l|}{ Residence } \\
\hline Urban & 92 & 90.2 \\
\hline Rural & 10 & 9.8 \\
\hline \multicolumn{3}{|l|}{ Monthly Income ${ }^{* *}$ (Taka) } \\
\hline$<10000$ & 4 & 3.9 \\
\hline $10000-20000$ & 35 & 34.4 \\
\hline $20000-30000$ & 25 & 34.4 \\
\hline$\geq 30000$ & 38 & 37.3 \\
\hline \multicolumn{3}{|l|}{ BMI\# (kg/m2) } \\
\hline $18.5-24.9$ (Normal) & 61 & 59.8 \\
\hline 25 - 29.9 (Overweight) & 34 & 33.3 \\
\hline$\geq 30$ (Obese) & 7 & 6.9 \\
\hline
\end{tabular}

${ }^{*}$ Mean age $=26.4 \pm 5.5 \mathrm{yrs} ; *$ Mean income $=29460 \pm 2180$ Taka; "Mean BMI $=25.4 \pm 3.4 \mathrm{yrs}$.

\begin{tabular}{|c|c|c|}
\hline Obstetric characteristics & Frequency & Percentage \\
\hline \multicolumn{3}{|l|}{ Gestation age (weeks) } \\
\hline $34-36$ & 8 & 7.8 \\
\hline $37-39$ & 68 & 66.7 \\
\hline $40-41$ & 26 & 25.5 \\
\hline \multicolumn{3}{|l|}{ Parity } \\
\hline Nullipara & 67 & 65.7 \\
\hline Primipara & 15 & 14.7 \\
\hline Multipara & 20 & 19.6 \\
\hline \multicolumn{3}{|l|}{ ANC } \\
\hline Regular & 62 & 60.8 \\
\hline Irregular & 40 & 39.2 \\
\hline \multicolumn{3}{|c|}{$\begin{array}{l}\text { TABLE III. Distribution of respondents by serum vitamin B12 } \\
\text { status }(n=102)\end{array}$} \\
\hline Serum vitamin $B_{12}$ & Frequency & Percentage \\
\hline$<200$ & 36 & 35.3 \\
\hline$\geq 200$ & 66 & 64.7 \\
\hline
\end{tabular}

*Mean serum vitamin $=208.0 \pm 50.7 \mathrm{pg} / \mathrm{ml}$; range $=60-294.4 \mathrm{pg} / \mathrm{ml}$

\begin{tabular}{|c|c|c|c|}
\hline \multirow{2}{*}{$\begin{array}{l}\text { Demographic } \\
\text { features }\end{array}$} & \multicolumn{2}{|c|}{ Serum vitamin B12 (pg/ml) } & \multirow[b]{2}{*}{$p$-value } \\
\hline & $<200(n=36)$ & $\geq 200(n=66)$ & \\
\hline Age $^{*}(y r s)$ & $27.2 \pm 4.3$ & $25.9 \pm 6.1$ & 0.252 \\
\hline $\begin{array}{l}\text { Monthly family } \\
\text { income* (Taka) }\end{array}$ & $19375 \pm 1703$ & $35967 \pm 3162$ & $<0.001$ \\
\hline \multicolumn{4}{|l|}{ Education ${ }^{\#}$} \\
\hline Primary & 14(38.9) & $17(25.8)$ & 0.049 \\
\hline SSC & $12(33.4)$ & $12(18.2)$ & \\
\hline HSC & $6(16.7)$ & $22(33.3)$ & \\
\hline Graduate plus & $4(11.0)$ & $15(22.7)$ & \\
\hline \multicolumn{4}{|l|}{ Parity" } \\
\hline Nullipara & 23(63.9) & $44(66.7)$ & 0.970 \\
\hline Primipara & $6(16.7)$ & $9(13.6)$ & \\
\hline Multipara & $7(19.5)$ & 13(19.7) & \\
\hline $\mathrm{BMI}^{*}(\mathrm{~kg})$ & $24.8 \pm 3.4$ & $25.9 \pm 3.4$ & 0.124 \\
\hline
\end{tabular}

Figures in the parentheses denote corresponding percentage; \# Data were analysed using $\chi^{2}$ Test.

*Data were analysed using Unpaired t-Test and were presented as mean \pm SD.

\begin{tabular}{|c|c|c|c|}
\hline \multirow{2}{*}{$\begin{array}{l}\text { Food } \\
\text { behaviour-related } \\
\text { variables }\end{array}$} & \multicolumn{2}{|c|}{ Serum vitamin $B_{12}$} & \multirow[b]{2}{*}{ p-value } \\
\hline & $\begin{array}{l}<200 \\
(n=36)\end{array}$ & $\begin{array}{c}\geq 200 \\
(n=66)\end{array}$ & \\
\hline Median fish days in a week* & $2.1 \pm 0.9$ & $3.3 \pm 1.7$ & $<0.001$ \\
\hline Median meat days in a week* & $1.9 \pm 0.3$ & $2.2 \pm 0.2$ & 0.301 \\
\hline $\begin{array}{l}\text { Mean number of eggs } \\
\text { taken in a week* }\end{array}$ & $1 \pm 1$ & $3 \pm 1$ & $<0.001$ \\
\hline $\begin{array}{l}\text { Mean amount of milk } \\
\text { in a week* (liter) }\end{array}$ & $0.33 \pm 0.13$ & $0.88 \pm 0.11$ & 0.001 \\
\hline
\end{tabular}

Figures in the parentheses denote corresponding percentage; * Data were analysed using Unpaired t-Test and were presented as mean $\pm \mathrm{SD}$.

\begin{tabular}{|c|c|c|c|}
\hline \multirow{2}{*}{$\begin{array}{l}\text { Outcome } \\
\text { variables }\end{array}$} & \multicolumn{2}{|c|}{ Serum Vitamin $B_{12}(\mathrm{p} \mathrm{g} / \mathrm{ml})$} & \multirow{2}{*}{$\mathrm{p}$-value } \\
\hline & $<200(n=36)$ & $\geq 200(n=66)$ & \\
\hline \multicolumn{4}{|l|}{ Birth weight (kg) } \\
\hline$<2.5$ & $12(33.3)$ & $4(6.1)$ & \multirow{3}{*}{$<0.001$} \\
\hline$\geq 2.5$ & $24(66.7)$ & $62(93.3)$ & \\
\hline Mean $\pm S D^{*}$ & $2.6 \pm 0.4$ & $3.1 \pm 0.7$ & \\
\hline Small-for-date ${ }^{\#}$ & $10(27.8)$ & $4(6.1)$ & 0.002 \\
\hline Neural tube defect** & $2(5.6)$ & $0(0.0)$ & 0.133 \\
\hline Other congenital malfor & ion** 2(5.6) & $1(1.5)$ & 0.279 \\
\hline
\end{tabular}

Figures in the parentheses denote corresponding percentage; *Data were analysed using Unpaired t-Test and were presented as mean \pm SD.

\#Data were analysed using $\chi^{2}$ Test;

**Data were analysed using Fisher's Exact Test 


\section{DISCUSSION:}

The present study demonstrated that subclinical vitamin $B_{12}$ deficiency of pregnant women is associated with their food behaviour and carries a higher risk of adverse perinatal outcome. The pregnant women with low serum vitamin $B_{12}$ (< $200 \mathrm{pg} / \mathrm{ml}$ ) had significantly lower weekly consumption of fishes and eggs which are the rich source of vitamin $B_{12}$. The weekly fish consumption of pregnant women with low serum vitamin $B_{12}$ was on an average 1 day less than the pregnant women with normal serum vitamin $B_{12}$. The average number of eggs taken weekly by the former group was less than that taken by the latter group. The amount of milk taken by the pregnant women with low serum vitamin $B_{12}$ was drastically lower than their counterparts with normal serum vitamin $B_{12}$ level. Of 102 pregnant women, 36 (35.3\%) had serum vitamin $\mathrm{B}_{12}<200$ $\mathrm{pg} / \mathrm{mL}$, which is higher than a recent study conducted on non-pregnant Bangladeshi women (22\%) (Survey on Micronutrients, 2013) ${ }^{18}$ but much lower than that found in a study conducted on non-pregnant Jordanian women (67\%). Guerra-shinohara and colleagues (2004) have described a $37.3 \%$ decrease in vitamin $B_{12}$ levels from the beginning to the end of pregnancy in Brazilian women. This fall is thought to be physiological, owing to an increase in plasma volume and a change in hormonal status ${ }^{19}$ and an increase in the requirements of the vitamin, secondary to pregnancy. ${ }^{20}$ In a study of nutritional factors related to anaemia in pregnant women attending an antenatal clinic in Nigeria, ${ }^{21} 9 \%$ of pregnant women had serum vitamin $B_{12}$ levels below the lower end of the normal range. Chéry and colleagues ${ }^{22}$ found that low vitamin $B_{12}$ levels in the third trimester of pregnancy correlated with a rise in plasma total homocysteine during this time and suggested that subclinical deficiency may start to appear at this stage, particularly in mothers on diets deficient in animal foods. As inadequate vitamin $B_{12}$ increases the risk of adverse maternal and foetal outcome, ${ }^{8,23}$ over one-third of the pregnant women in our study were at increased risk of adverse perinatal outcome.

The present study also observed a significantly inverse association of income and education with vitamin $B_{12}$ level with higher the income and level of education lower is the probability of having low serum vitamin $B_{12}$. Muthayya and associates ${ }^{24}$ suggest that a low educational level, poor anthropometric status in early pregnancy, low weight gain in the second trimester of pregnancy $\&$ a low serum vitamin $B_{12}$ concentration throughout pregnancy are significant determinants of IUGR (Intrauterine Growth Restriction) in urban Indian women. The inverse relationship between maternal educational level and risk of IUGR persists even after adjusting for maternal age, parity and maternal weight in early pregnancy. Several other studies also reported maternal illiteracy and low socioeconomic status to be the major risk factors for IUGR. ${ }^{25,26}$

In the present study, the perinatal outcome of pregnant women with low serum vitamin $B_{12}$ was unfavourable in terms of birth weight and small-for-date babies. Low serum vitamin $B_{12}$ was found in $15.6 \%$ of the cases, which is much lower than the published national figure (36\%). ${ }^{27}$ This might be due to tertiary hospital-based study, which may not be the true representative of the community population. However, analyses of association between maternal serum vitamin $B_{12}$ and perinatal outcome revealed a significantly lower mean birth weight (on an average $0.5 \mathrm{~kg}$ less) and a higher incidence of small-for-date neonates (on an average $22 \%$ higher) in pregnant women with low serum vitamin $\mathrm{B}_{12}$ compared to those in normal serum vitamin $B_{12}$ level.

Muthayya and colleagues ${ }^{24}$ demonstrated that women in the lowest tertile for vitamin $B_{12}$ concentration during each of the three trimesters of pregnancy had significantly higher risk of IUGR (adjusted $\mathrm{OR}=5.98$ ). They also reported that better socioeconomic conditions and improved nutritional status well-correlates with vitamin $B_{12}$ status during pregnancy, which in turn, reduces 
the incidence of IUGR. An earlier study reported negative correlations between birth weight and maternal vitamin $\mathrm{B}_{12}$ levels at delivery in smokers in Western women, ${ }^{28}$ although present study did not investigate smoking habit of the selected women, which might act as a confounder. Thus, the findings suggest that early detection of vitamin $B_{12}$ deficiency in pregnancy followed by appropriate intervention are likely to play an important role in reducing IUGR which contributes substantially to low birth weight \& small-for-dates. Molloy \& associates ${ }^{29}$ demonstrated that starting pregnancy with an inadequate vitamin $B_{12}$ status may increase the risk of birth defects such as NTD, and may contribute to preterm delivery, although NTD in the present study was not significantly associated with women of low serum vitamin $\mathrm{B}_{12}$ level.

Nutritional status during pregnancy has a direct influence upon birth weight. Adequate supply of micronutrients is known to be very important in pregnancy and there is much evidence to support a role of folate in early embryonic development. ${ }^{30}$ A clear causal association has been shown between reduced maternal folate and neural tube defects $^{31,32}$ and other congenital malformations ${ }^{33}$ as well as early pregnancy loss. ${ }^{34}$ More recently Rao et al $^{35}$ observed a positive association between infant birth weight and dietary intake of folate-rich foods in rural Indian women. So maternal diet during pregnancy is highly important for the health of the fetus. ${ }^{35}$

Vitamin $B_{12}$ plays an integral role in folatedependent homocysteine metabolism ${ }^{36}$ as a ratelimiting co-factor in the conversion of homocysteine to methionine and a limited supply of vitamin $B_{12}$ during pregnancy may have adverse consequences on fetal growth. Furthermore, low serum levels of maternal vitamin $B_{12}$ have been associated with risk of neural tube defect-affected pregnancy. ${ }^{37,38}$ Vitamin $B_{12}$ is known to be a significant predictor of tHcy levels in neonates, with relatively greater importance in the first few months of life, before folate assumes primacy as the predictor of thcy (total serum homocysteine).
A deficiency of either vitamin $B_{12}$ and/or folic acid is likely to affect homocystine metabolism, resulting in an elevation of plasma homocystine with relatively low methionine level. During pregnancy an increase Hcy (Homocysteine) level has been shown to be a risk factor for IUGR, intrauterine death, neural tube defects and low birth weight. Murphy and associates ${ }^{39}$ have reported that mothers in the highest total Hcy tertile at 8 weeks of pregnancy had three times and at labour nearly four times the odds of giving birth to a neonate in the lowest birth weight tertile. The role of vitamin $B_{12}$ in pregnancy outcome has been explored by Molloy et al. ${ }^{29}$ who suggested that vitamin $B_{12}$ status may be an important factor in maintaining optimal tHcy during pregnancy, although the potential role of vitamin $B_{12}$ in the determination of birth weight has yet to be explored. Therefore, additional studies are needed to elucidate the role of vitamin $\mathrm{B}_{12}$ together with $\mathrm{Hcy}$ in the prevention of adverse outcomes.

The present study had several limitations which deserve mention so that future studies on the same issue could overcome the limitations faced in the present one.

\section{LIMITATIONS:}

1. The food behaviour of the women was assessed by 7-days dietary recall, which might be inherently associated with recall bias.

2. As studies by other researchers have shown that folate $\&$ homocystine are also associated with maternal and perinatal outcome, it cannot be over-emphasized that the adverse perinatal outcome attained in the pregnant women have had occurred solely due to low serum vitamin $\mathrm{B}_{12}$.

\section{CONCLUSION:}

From the findings of the study it can be concluded that over one-third of the Bangladeshi pregnant women possess low vitamin $B_{12}$. The pregnant women with low serum vitamin $\mathrm{B}_{12}$ are used to taking low fish and eggs in their daily diet 
compared to those who have normal serum vitamin $\mathrm{B}_{12}$. The milk consumption of the pregnant women are also much lower than their counterparts with normal serum vitamin $\mathrm{B}_{12}$ level. The incidence of low birth weight and small-for-date babies are more prevalent in the pregnant women with subclinical deficiency of vitamin $B_{12}$. So a well-correlation is observed between pregnant women of low-socioeconomic group and their food-behaviour, between food-behaviour and their serum vitamin $B_{12}$ status and vitamin $B_{12}$ status during pregnancy and perinatal outcome.

\section{REFERENCES:}

1. Guerra-Shinohara EM, Morita OE, Peres S, Pagliusi RA, SampaioNeto LF, D'Almeida $V$ et al. Low ratio of $\mathrm{S}$-adenosyl $\neg$ methionine to S-adenosylhomocysteine is associated with vitamin deficiency in Brazilian pregnant women and newborns. Am J Clin Nutr 2004;80: 1312-21.

2. Cikot RJ, Steegers-Theunissen RP, Thomas CM, de Boo TM, Merkus HM, Steegers EA. Longitudinal vitamin and homocycteine levels in normal pregnancy. $\mathrm{Br} J \mathrm{Nutr}$ 2001;85:49-58.

3. Allen LH. Folate and vitamin B12 status in the Americas. Nutr Rev 2004;62:S29-S34.

4. Herbert V. Staging vitamin B12 status in vegetarians. Am J Clin Nutr 1994;59(Suppl):213S-22S.

5. Stipanuk M.Folic acid, vitamin B12 and vitamin B6. In: Biochemical and Physiological Aspects of Human Nutrition. 2001:483-518.

6. Lovblad K, Ramelli G, Remonda L, Nirkko AC, Ozdoba C, Schroth G. Retardation of myelination due to dietary vitamin B12 deficiency: cranial MRI findings. Pediatr Radiol 1997;27:155-8.

7. Rezinkoff-Etievant MF, Zittoun J, Vaylet C, Pernet $P$, Milliez J.Low vitamin B12 as a risk factor for very early recurrent abortion. Euro J Obste Gynaecol Reprod Biol 2002;104:156-9.

8. Refsum H.Folate, vitamin B12 and homocysteine in relation to birth defects and pregnancy outcome. $\mathrm{Br} J$ Nutr 2001;85:S109-13.

9. Ray JG, Blom HJ.Vitamin B12 insufficiency and the risk of fetal neural tube defects. Quart J Med 2003;96: 289-95.
10. Groenen PM, van Rooij IA, Peer PG, Gooskens $R H$ Zeilhuis JA, Steeger-Theunissen RP. Marginal materna vitamin B12 status increases the risk of offspring with spina-bifida. Am J Obstet Gynaecol 2004;191:11-7.

11. Gaber KR, Farag MK, Soliman SE, El-Bassyouni HT, El-Kamah G.Maternal vitamin B12 and the risk of fetal neural tube defecet in Egyptian patients. Clin Lab 2007;53:69-75.

12. Ray JG, Wyatt PR, Thompson MD, Vermeluen MJ, Meier C, Wong P-Y.Vitamin B12 and the risk of neural tube defects in folic-acid-fortified population. Epidemio 2007; 18:362-6

13. Obeid R, Morkbak AL, Munz W, Nexo E, Hernnann W. The cobalamin-binding proteins transcobalamin and haptocorrin in maternal and cord blood sera at birth. Clin Chem 2006;52:263-9.

14. Carmel R, Searri M.Diagnosis and management of sub-clinical cobalamin deficiency: advances \& controversies Current Haematol Reports 2006; 5:23-33.

15. Carmel R.Current concepts in cobalamin deficiency Annual Rev Med 2000;51:357-75.

16. Neuman C, Harris DM, Rogers LM.Contribution animal source food in improving diet quality and function in children in developing world. Nutrition Research 2002;22:193-220.

17. Wokes F, Badenoch J Sinclair HM. Human dietary deficiency of vitamin B12. AM J Clin Nutr 1955;3: 375-82

18. Anonymus. A survey carried out jointly by IPHN, UNICEF and Global Alliance (GAIN) for Improved Nutrition, $17^{\text {th }}$ Feb, 2013

19. Bruinse HW, van der Berg H.Changes of sum vitamin levels during and after normal pregnancy. Eur JO bstet Gynecol Reprod Biol 1995;61:31-7.

20. Gadowsky SL, Gale K, Wolfe SA, Jory J, Gibson R, O'Connor DL.Biochemical folate, B12, and iron status of a group of pregnant adolescents accessed through the Public Health System in Southern Ontario. J Adolesc Health $1995 ; 16: 465-74$.

21. Vanderjagt DJ, Brock HS, Melah GS, El-Nafaty AU, Crossey MJ, Glew RH.Nutritional factors associated with anemia in pregnant women in Northern Nigeria. J Health Pop Nutr 2007;25:75-81.

22. Chéry $C$, Barbé $F$, Lequere $C$, Abdelmouttaleb I, Gérard $P$, Barbarino $P$, Boutroy JL, Guéant JL. Hyperhomocysteinemia is related to a decreased blood level of vitamin $B_{12}$ in 
the second and third trimester of normal pregnancy. Clin Chem Lab Med 2002;40(11):1105-8.

23. Adams MJ, Khoury MJ, Scanlon KS, Stevenson RE, Knight G, Haddow JE, et al.Elevated midtrimester serum methyl $\neg$ malonic acid levels as a risk factor for neural tube defects.Teratology 1995;51:311-7.

24. Muthayya $\mathrm{S}$, Kurpad $\mathrm{AV}$, Duggan $\mathrm{CP}$, Bosch RJ, Dwarkanath $\mathrm{P}$, Mhaskar A et al. Low maternal vitamin B12 status is associated with intrauterine growth reduction in urban South Indians. Euro J Clin Nutr 2006;60:791-801.

25. Mavalankar DV, Gray RH, Trivedi CR. Risk factors for preterm and term low birth weight in Ahmedabad, India. Int J Epidemiol 1992;21:263-72.

26. Fikree FF, Berendes HW. Risk factors for intrauterine growth retardation: a community-based study in Karachi. Bull WHO 1994;72:581-7.

27. Bangladesh Demographic and Health Survey (BDHS), NIPORT, 2011.

28. Frery N, Huel G, Leroy M, Moreau T, Savard R, Blot P et al.Vitamin B12 among parturients and their newborns and its relationship with birth weight. Eur J Obstet Gynaecol Reprod Biol 1992;45:155-63.

29. Molloy AM, Kirke PN, Brody LC, Scott JM, Mills JL. Effects of folate and vitamin B12 deficiencies during pregnancy on fetal, infant, and child development. Food Nutr Bull 2008;29(2):S101-S112.

30. Rosenquist TH, Finnell RH. Genes, folate \& homocysteine in embtyonic development. Proceedings of the Nutrition Society $2001 ; 60(1): 53-61$.

31. MRC; MRC Vitamin Study Research Group. Prevention of neural tube defects: results of the Medical Research Council Vitamin Study. Lancet 1991;338:131-37.
32. Czeizel $A E$, Dudas I. Prevention of the first occurrence of neural-tube defects by periconceptional vitamin su: lementation. N Engl J Med 1992;327:1832-35.

33. Botto LD, Khoury MJ, Mulinare J, Erickson JD. Periconceptional multivitamin use and the occurrence of conotruncal heart defects: results from a population-based, case-control study. Pediatrics 1996; 98(5):911-7.

34. Nelen $\mathrm{WL}$, Blom HJ, Steegers EA, den Heijer $\mathrm{M}$, Thomas $\mathrm{CM}$, Eskes TK. Homocysteine and folate levels as risk factors for recurrent early pregnancy loss. Obstet Gynecol 2000;95(4):519-24.

35. Rao S, Yajnik CS, Kanade A, Fall $\mathrm{CH}$, Margetts $B M$, Jackson AA, Shier R, Joshi S, Rege S, Lubree H, Desai $B$. Intake of micronutrient-rich foods in rural Indian mothers is associated with the size of their babies at birth: Pune Maternal Nutrition Study. J Nutr 2001;131(4):1217-24.

36. Refsum H. Folate, vitamin B12 and homocysteine in relation to birth defects and pregnancy outcome. $\mathrm{Br} \mathrm{J}$ Nutr 2001;85(Suffel 2):S109-13.

37. Kirke PN, Malloy AM, Daly LE, Burke H, Weir DG, Scott JM. Maternal plasma folate and vitamin B12 are independent risk factors for nural tube defects. $Q J$ Med 1993; $86: 703-8$.

38. Suarez L, Hendricks K, Felkner M, Gunter E.Maternal serum B12 levels and risk for neural tube defects in a Texas-Mexico border population. Ann Epidemiol 2003; 13(2):81-8.

39. Murphy MM, Scott JM, Arija V, Molloy AM, FernandezBallart JD. Maternal homocystine before conceptionand throughout pregnancy predicts foetalhomocystine and birth weight. Clin Chem 2004;50:1406-12. 